\title{
Developmental pathway genes and neural plasticity underlying emotional learning and stress-related disorders
}

\author{
Marissa E. Maheu and Kerry J. Ressler \\ Department of Psychiatry, McLean Hospital, Harvard Medical School, Belmont, Massachusetts 02478, USA
}

\begin{abstract}
The manipulation of neural plasticity as a means of intervening in the onset and progression of stress-related disorders retains its appeal for many researchers, despite our limited success in translating such interventions from the laboratory to the clinic. Given the challenges of identifying individual genetic variants that confer increased risk for illnesses like depression and post-traumatic stress disorder, some have turned their attention instead to focusing on so-called "master regulators" of plasticity that may provide a means of controlling these potentially impaired processes in psychiatric illnesses. The mammalian homolog of Tailless (TLX), Wnt, and the homeoprotein Otx2 have all been proposed to constitute master regulators of different forms of plasticity which have, in turn, each been implicated in learning and stress-related disorders. In the present review, we provide an overview of the changing distribution of these genes and their roles both during development and in the adult brain. We further discuss how their distinct expression profiles provide clues as to their function, and may inform their suitability as candidate drug targets in the treatment of psychiatric disorders.
\end{abstract}

In the past two decades it has become clear that many forms of neural plasticity once believed unique to early development are in fact recapitulated in the adult brain during learning. A vast body of literature has since focused on identifying and characterizing these various neuroplastic processes, as well as the long list of molecular regulators that may play a role in mediating this plasticity. The sheer breadth of candidate genes and molecules that contribute to each of these processes has, in turn, reinvigorated interest in the identification of so-called "master regulators" of plasticity. Yet there remains no clear definition for what constitutes a "master regulator," with no detailed accounting of what characteristics such regulators of neural plasticity share. Nor, importantly, is there any consensus as to whether any shared features they may possess can be used to categorize regulators of plasticity in a manner that helps inform their function.

Neural plasticity can be broadly defined as the alteration of structural features of neurons that result in changes in interneural communication. Such changes may be long- or short-term, ultraor macrostructural in nature; they may be limited to the molecular reorganization of individual synapses, extend to neuron-wide changes in intrinsic excitability, or even involve the generation of entirely new neurons (for review, see Fioravante and Regehr 2011; McEwen et al. 2012; Ehrlich and Josselyn 2016). Together, these various forms of neuronal remodeling are believed to underlie the brain's remarkable capacity to learn and remember. The foundational studies implicating neural plasticity in these functions were conducted in Aplysia californica and provided the first direct evidence that manipulating synaptic plasticity can result in behavioral changes-in this case, sensitization of the gill withdrawal reflex (for an excellent narrative review of the evolution of the field of neural plasticity, see Sweatt 2016). Since these initial explorations, a large number of environmental factors have been shown to alter various forms of neural plasticity in a temporal- or developmental period-dependent manner, issues we

\section{Corresponding author: kressler@partners.edu}

Article is online at http://www.learnmem.org/cgi/doi/10.1101/lm.044271. 116. discuss in greater detail below (McEwen et al. 2012; Callaghan and Tottenham 2016; Ehrlich and Josselyn 2016).

It is generally accepted that the regulation of neural processes underlying learning is not strictly hierarchical. Instead, a web of interacting messengers and mediators work in tandem to shape various aspects of function and plasticity. In addition to the complexity inherent in disentangling the relative contributions and import of overlapping networks, the number of molecular classes that seem to play a role in the regulation of plasticity has increased dramatically over the past decade, and shows no sign of slowing. Noncoding RNAs, transcription factors, microRNAs, histone deacetylases, and receptors with their secreted ligands of every description have all been implicated in the organization and execution of structural remodeling. Furthermore, the relative import of any given molecular class or network varies from brain region to brain region and depends upon many factors including local architecture, cellular heterogeneity and composition, and innate capacity for remodeling.

Despite the hope that large-scale genome-wide association studies (GWAS) would reveal key molecular contributors to the development of complex, stress-related psychiatric disorders, so far this approach has been unable to provide more than a handful of candidate therapeutic targets that are both targetable and broadly implicated in the etiology of these illnesses (Smoller 2016; Banerjee et al. 2017). Instead, GWAS and related approaches have provided a strong argument for the view that many stress-related disorders are associated with dysregulation among common subsets of cellular processes. If such studies have thus far failed to reveal the precise source of genetic risk, they have at least pointed us in the direction of which cellular functions may hold the most promise in ameliorating the outcome.

\footnotetext{
(C) 2017 Maheu and Ressler This article is distributed exclusively by Cold Spring Harbor Laboratory Press for the first 12 months after the full-issue publication date (see http://learnmem.cshlp.org/site/misc/terms.xhtml). After 12 months, it is available under a Creative Commons License (AttributionNonCommercial 4.0 International), as described at http://creativecommons. org/licenses/by-nc/4.0/.
} 
Among the processes implicated in stress-related disorders, neural plasticity-related pathways have consistently arisen as key mediators of psychiatric risk and treatment response, and their relevance to both illness and pharmacological intervention has been supported by multiple avenues of research (Kilaru et al. 2016; Sato et al. 2016; Xie et al. 2017). Yet, given that neuroplasticity itself is an umbrella term that encompasses a wide array of functions, and that each of these is modulated by a long list of molecules that are inconsistently affected in disease, identifying the molecular fulcrums around which the processes of neurogenesis, synaptic remodeling, or circuit stabilization can be manipulated has proven difficult. The hope, nevertheless, is that regardless of the proximal cause of any given disruption in these processes, the resulting deficits can be at least partially alleviated by moving the entire system in one direction or another.

In evaluating candidate "master regulators" of plasticity that may fulfill such a task, it is not enough to enumerate what processes they regulate. We must also consider when they do so. As will be discussed below, the multidimensional profile of key molecular players in brain patterning, cellular maturation, and synapse formation can inform their function as well as the feasibility of using them as regionally specific and therapeutic targets.

In the present review, we provide a brief summary of how three candidate regulators of neuroplasticity-TLX, Wnts, and Otx2-contribute to both neural development and structural remodeling within adult circuits, with an eye to highlighting how their differing patterns of expression and roles throughout maturation inform their function in learning.

\section{TLX}

The orphan nuclear receptor subfamily 2 group E member 1 (NR2E1), commonly referred to as tailless or TLX, is a key regulator of neurogenesis and of neural stem cell population maintenance (for a detailed review, including TLX's role in retinal development see Islam and Zhang 2015). In the developing mouse brain, TLX transcripts are first detected on embryonic day 8 (E8), with expression spreading from the prosencephalon into the diencephalon soon thereafter. Upon fusion of the neural fold, TLX expression extends both rostrally and caudally, with expression of this highly conserved transcription factor apparent throughout the developing forebrain at maximal levels by E11.5 (Yu et al. 1994; Monaghan et al. 1995). By E13.5, TLX mRNA content begins to decrease in all brain regions and is already substantially reduced by E15.5 (Monaghan et al. 1995; Allen Developing Mouse Brain Atlas 2008; Thompson et al. 2014). However, despite globally decreased expression at birth in vertebrates, patches of high TLX expression are maintained in the ventricular and subventricular zones (extending into the rostral migratory stream), as well as in the neural epithelium from which the optic stalk arises (Monaghan et al. 1995). Although expression of TLX in the adult brain has been reported to exceed that seen immediately after birth (Monaghan et al. 1995), TLX expression nevertheless appears to remain relatively limited and primarily localized to a small subset of tissues in mature mammals, including the adrenal and thyroid glands, testis, placenta, bone marrow, and neurogenic regions of the brain (Allen Mouse Brain Atlas 2004; Nishimura et al. 2004; Lein et al. 2007; Zhang et al. 2008). Thus, temporal and topographical expression patterns of TLX in the brain mirror mitotic activity; its role remains fixed while its regional expression and distribution dictate where its activity contributes to neuronal plasticity (Fig. 1).

TLX's status as a master regulator of plasticity derives from its indispensability for proper cell cycle progression and its broad influence on astroglio- and neurogenesis. Neurogenesis is the process by which activated neural stem cells (NSCs) proliferate, forming transit amplifying cells which in turn migrate to other brain regions and differentiate into mature neurons in order to integrate
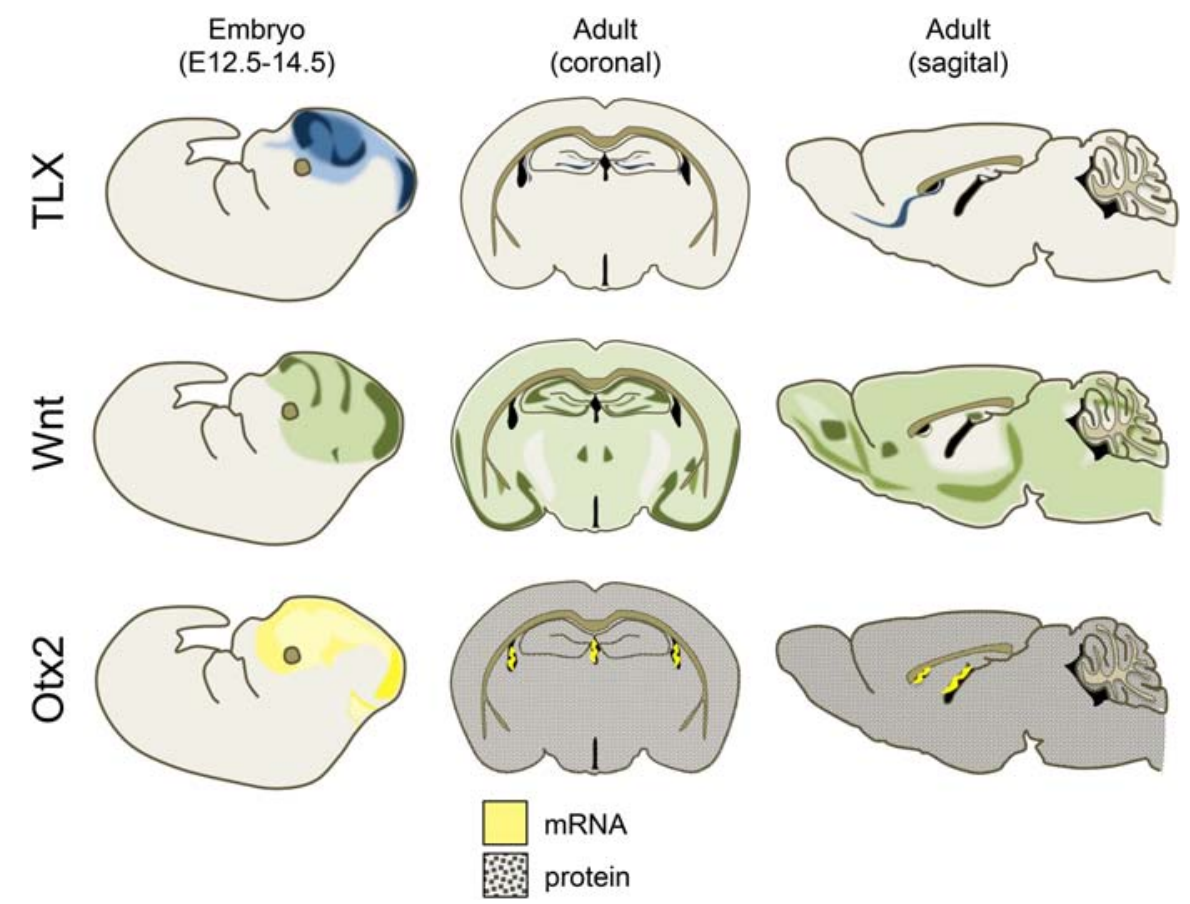

Adult

Figure 1. Schematic depicting expression of TLX, Wnt, and Otx 2 in the brain of embryonic and adult mice. TLX: TLX is extensively expressed during early and mid embryonic development. From late embryonic development onward, TLX expression narrows to regions in which neurogenesis is maintained, including the dentate gyrus of the hippocampus, the subventricular zone, and rostral migratory stream. Images were recreated using the following sources: Islam and Zhang 2015; Liu et al. 2008; Lein et al. 2007; 2008 Allen Institute for Brain Science. Allen Developing Mouse Brain Atlas. Available from: developingmouse.brain-map.org; 2004 Allen Institute for Brain Science. Allen Mouse Brain Atlas. Available from: mouse.brain-map.org. Wnt: Canonical Wnt signaling during early embryonic development as visualized by TCF/Lef-LacZ expression is broadly distributed throughout the embryonic brain, with regions of greater expression along the superciliary arch, developing frontal cortex, and midbrain. In the adult brain, Wnt1 expression is widespread but particularly elevated in ventral cortical regions, the hippocampus, whereas the amygdala displays moderate Wnt1 expression. Images were recreated using the following sources: Maguschak and Ressler 2012; Mani et al. 2010; Allen Developing Mouse Brain Atlas. Available from: developingmouse.brain-map.org; 2004 Allen Institute for Brain Science. Allen Mouse Brain Atlas. Available from: mouse.brain-map.org. Otx2: Otx2 is prominently expressed throughout the embryonic mouse diencephalon and mesencephalon, but post-natally Ot 2 mRNA production in the brain is restricted to the choroid plexus localized in the lateral and third ventricles. Otx2 protein, on the other hand, is released and circulates in the cerebrospinal fluid, before being sequestered by parvalbumin-expressing interneurons in multiple brain regions. Images were recreated using the following sources: Courtois et al. 2003; Fossat et al. 2005, 2007; Allen Developing Mouse Brain Atlas. Available from: developingmouse.brain-map.org; 2004 Allen Institute for Brain Science. Allen Mouse Brain Atlas. Available from: mouse.brain-map.org. 
into functional neural circuits. TLX knockout mice display cortical thinning as early as E14.5, with maximal neuronal loss in superficial layers (Land and Monaghan 2003). These neurogenic deficits are attributable to reduced proliferation in germinal zones and reduced rates of cell division among progenitors as well as with premature cell cycle exit (Roy et al. 2004; Li et al. 2008), impairments that continue throughout development and into adulthood in TLX null mice. In the absence of TLX, ordinarily neurogenic regions in the adult brain such as the hippocampus and subventricular zone display an ectopic accumulation of quiescent NSCs that fail to produce neural progeny, while knock-down of TLX in transit amplifying cells biases differentiation toward a glial fate (Liu et al. 2008; Obernier et al. 2011; Li et al. 2012; Niu et al. 2011). These effects occur in tandem with increased expression of the astrocytic markers $\mathrm{S} 100 \beta$, glial fibrillary acid protein, and AQP4, supporting the view that TLX's role in maintaining undifferentiated cellular states depends upon its function as a transcriptional repressor (Shi et al. 2004). Notably, administration of exogenous TLX is sufficient to repress the glia-associated proteins listed above and to reactivate NSCs rendered quiescent by TLX knock-down (Shi et al. 2004; Niu et al. 2011). Finally, a recent report suggests TLX also regulates cellular senescence ( $\mathrm{O}^{\prime}$ Loghlen et al. 2015).

Since this early work characterizing TLX's function in maintaining the brain's neurogenic niches, several additional targets of TLX have been identified, many of which are directly implicated in regulating cell proliferation and differentiation. For instance, a 2008 study by Zhang et al. (2008) reported that deletion of TLX in adult hippocampal NSCs altered expression of over 200 genes, 45 of which are known modulators of cell cycle dynamics, DNA replication, or proliferation. Among these: MASH1 (Elmi et al. 2010), bone morphogenetic protein (Qin et al. 2014), and PTEN, whose repression by TLX has been shown to depend upon the recruitment of histone deacetylase HDAC5 (Sun et al. 2007). More recently, multiple studies have reported bidirectional interactions between TLX and microRNAs, providing an additional layer of complexity to TLX-mediated transcriptional regulation (Zhao et al. 2013; Ni et al. 2014; Huang et al. 2015; Murai et al. 2016). Finally, TLX has been shown to maintain stem cell renewal and induce proliferation via activation of the Wnt pathway, another major regulator of plasticity which we discuss below $(\mathrm{Qu}$ et al. 2010; O'Loghlen et al. 2015).

Behaviorally, TLX-null mutant mice display increased aggression, altered anxiety-like behavior, and impaired cue and contextual fear conditioning (Roy et al. 2002). However, it seems that many of these deficits are primarily attributable to the altered developmental trajectory and gross morphological abnormalities associated with early loss of TLX. Spontaneous germline deletion of TLX is associated with altered development of the olfactory bulbs and limbic system in C57BL/6J, 129P3/JEms, and B6129F1 mouse lines (Young et al. 2002). In particular, in germline TLX deletion animals, hippocampal size is markedly reduced, and dentate gyrus granule cells display reduced dendritic complexity (Roy et al. 2004; Christie et al. 2006).

Considerably less is known about the effects of adult deletion of TLX on behavior. Despite evidence that cell proliferation in the dentate gyrus is required for contextual fear conditioning, a 2008 report by Zhang et al. (2008) found that TLX knock-down during adulthood-and the subsequent $80 \%$ reduction in adult hippocampal neurogenesis-did not result in any fear conditioning deficit. However, these same mice displayed impaired short-term memory and delayed learning 4 wk after TLX knock-down on the Morris Water Maze task, a behavioral measure that is sensitive to reductions in adult dentate gyrus neurogenesis (Zhang et al. 2008; Gonçalves et al. 2016). Notably, the authors of this study reported that the need for adult hippocampal neurogenesis in spatial learning depended upon the training protocol used and, therefore, the task difficulty. Similar requirements may therefore exist for contextual fear conditioning, so given a more rigorous training protocol TLX deletion may yet prove to adversely affect outcome on these learning tasks. A recent report from Seo et al. (2015) lends support to this possibility. These authors found that ablating hippocampal neurogenesis either impaired or facilitated fear conditioning as a function of the strength of the aversive stimulus and the extent to which the conditioning paradigm recruited nonassociative plasticity.

Unfortunately, the report of Zhang and colleagues remains, to the best of our knowledge, the only exploration of the effects of adult deletion of TLX on behavior. However, a large body of literature implicates adult neurogenesis in the execution of a range of affective and cognitive processes including pattern separation, the temporal organization of memories, spatial learning, forgetting, and fear generalization, and a range of models postulating how these are achieved have been proposed (for a recent review, see Besnard and Sahay 2016; Gonçalves et al. 2016). Given the indispensability of TLX for maintaining neurogenesis in the adult brain, it is therefore probable that future research will provide a better understanding of the behavioral ramifications of TLX deletions or loss-of-function mutations.

Although neurogenesis is a complex process regulated by a vast array of molecules, the functional heterogeneity of many of these regulators make them ill-suited to attempting to modulate neurogenesis without altering other forms of plasticity in multiple brain regions. For instance, neurotrophins such as brainderived neurotrophic factor, permissive plasticity factors such as polysialylated neural cell adhesion molecule, and even other stem-cell markers like nestin, while crucial to neurogenic function, also appear to regulate diverse forms of plasticity in other brain areas (Guirado et al. 2014; Ehrlich and Josselyn 2016; Farzanehfar et al. 2017). Conversely, the highly regionalized nature of TLX expression in the adult brain makes this transcription factor an attractive candidate for future studies on its role in mediating neurogenesis directly and specifically, particularly in light of recent evidence suggesting that TLX may be a point of crosstalk between the neuroinflammatory response and reductions in hippocampal neurogenesis observed following stress (Ryan et al. 2013).

\section{Wnt}

In stark contrast to TLX, whose expression narrows to neurogenic regions post-natally, the Wnt signaling pathway represents a major regulator of neural plasticity whose expression remains elevated throughout the brain for the length of the mammalian lifetime. Instead of maintaining a consistent role, however, the contributions of Wnt signaling to neuroplasticity vary by region, and may mediate synaptic strength, synaptic stabilization, or neurogenesis depending upon the brain area in question. TLX, in comparison, is less versatile. Whereas TLX appears to maintain undifferentiated cellular states in whatever region it is expressed, increasing or decreasing Wnt expression has pleitropic effects depending upon where its expression is altered.

Wnt signaling occurs via both canonical and noncanonical signaling pathways which are either dependent upon or independent of interaction with $\beta$-catenin, respectively. The noncanonical pathway can be further subdivided into the Planar Cell Polarity and Wnt/ $/ \mathrm{Ca}^{2+}$ pathways (Habas and Dawid 2005). In addition to relying, or not, on the activity of $\beta$-catenin and its translocation to the nucleus in order to initiate or inhibit transcription of target genes, the activation of canonical or noncanonical pathways is frequently thought to be mediated by distinct members of the Wnt family. However, the reality seems to be more nuanced. A 
A
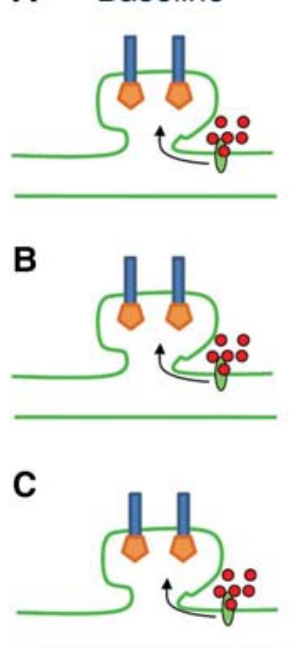
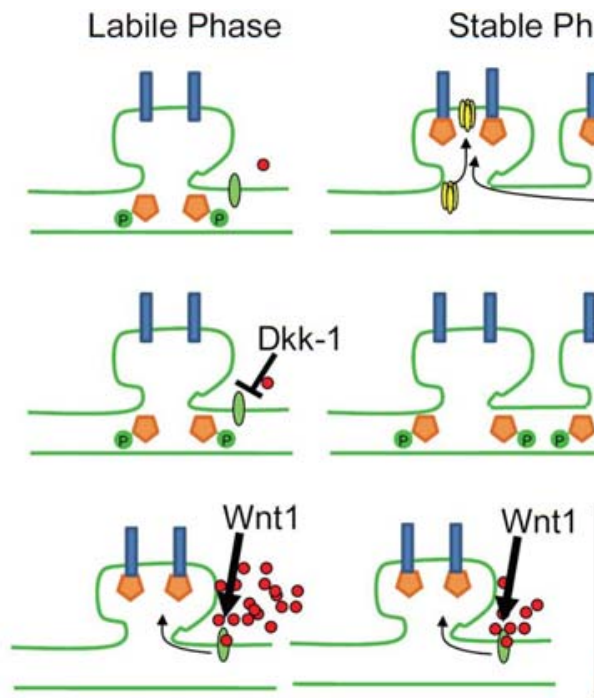

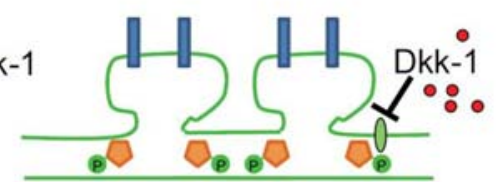

Stable Phase
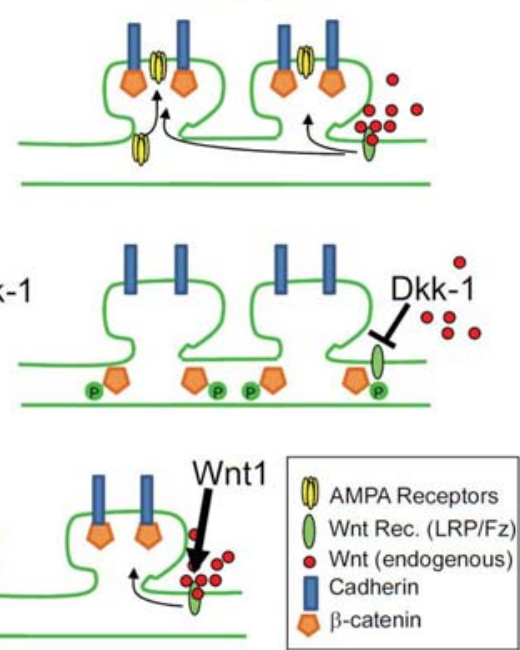

Figure 2. Schematic representation of canonical Wnt/ $\beta$-catenin signaling (figure taken from Maguschak and Ressler 2012).

compelling case has been made to support the importance of cell surface receptor complement, rather than the identity of individual Wnts themselves, in determining downstream signaling (van Amerongen et al. 2008).

Following binding of Wnt glycoproteins to the cell surface receptor Frizzled (Fz), a member of the seven transmembrane domain family, or a receptor complex comprising both $\mathrm{Fz}$ and low-density-lipoprotein-related-protein5/6 (Lrp5/6), signaling is transduced to Dishevelled (Dsh), a cytoplasmic phosphoprotein whose recruitment can induce signaling via all three pathways (for a detailed review of Wnt signaling, see Komiya and Habas 2008). In the case of canonical Wnt signaling, activation of Dsh allows $\beta$-catenin to translocate to the cell nucleus by inhibiting the activity of glycogen synthase kinase-3 (Gsk-3), which ordinarily marks $\beta$-catenin for proteasomal degradation via phosphorylation of Ser33/37 and Thr41 (Figs. 2 and 3). Upon entering the nucleus, $\beta$-catenin binds T-cell factor/lymphoid enhancer factor which, in turn, initiates transcription of Wnt target genes.

During embryonic development, Wnt ligand expression gradients regulate rostrocaudal, and later dorsal telencephalic regional specification, and regulate neural progenitor renewal and differentiation (Glinka et al. 1998; Lee et al. 2000; Kiecker and Niehrs 2001; Monuki et al. 2001; Megason and McMahon 2002; Machon et al. 2007; Munji et al. 2011). This latter role appears to be mediated by tonic expression of stabilized $\beta$-catenin which inhibits cellcycle exit among cortical progenitors, whereas inhibition of canonical Wnt signaling through $\beta$-catenin and increasing activity of the Wnt/Planar Cell Polarity pathway induces maturation (Chenn and Walsh 2002; Mutch et al. 2010; Schafer et al. 2015). However, these effects of Wnt signaling are closely tied to developmental stage, and therefore presumably the temporal expression patterns of coregulators of neuronal development, such as FGF2, which modulate cellular sensitivity to Wnt ligands (Israsena et al. 2004). For instance, during later developmental stages, Wnt7a has been shown to negatively regulate cellular expansion in the neocortex and instead promotes neural progenitor cell differentiation (Hirabayashi et al. 2004). In addition, individual Wnt ligands may act in an antagonistic manner, alternately promoting or inhibiting cell cycle exit within particular neuronal subpopulations via simultaneous activation of both canonical and noncanonical pathways (Andersson et al. 2013).
Wnt signaling remains a crucial regulator of neuronal proliferation and development in the neurogenic regions of the adult brain. In the mature hippocampus and subventricular zone, Wnts play a permissive role in both proliferation and differentiation, and Wnt/ $\beta$-catenin signaling guides progenitors toward a neuronal lineage (Lie et al. 2005; Adachi et al. 2007; Kuwabara et al. 2009; for a review of Wnt signaling in adult hippocampal neurogenesis, see Varela-Nallar and Inestrosa 2013). Inhibition of Wnt signaling by the secreted antagonist Dkk1 reduces proliferation in the subventricular zone and hippocampus and impairs hippocampal-dependent memory consolidation, whereas enhancing Wnt signaling via inhibition of Gsk-3 $\beta$ enhances hippocampal neurogenesis (Adachi et al. 2007; Fortress et al. 2013; Seib et al. 2013; Xu et al. 2015; Pérez-Domper et al. 2017). Likewise, deletion of the Wnt inhibitor secreted frizzled-related protein 3 activates quiescent stem cells in the dentate gyrus (Jang et al. 2013). However, Wnts' contributions to memory formation and maintenance extend beyond the neurogenic regions of the adult brain, and multiple lines of evidence suggest a primary role for Wnt-mediated regulation of preand postsynaptic structure (for a detailed review, see Inestrosa and Arenas 2010).

Within the amygdala and hippocampus, acute stress and fear conditioning are associated with the phosphorylation of Gsk-3 $\beta$, which occurs in tandem with altered $\beta$-catenin levels and/or stabilization, suggesting that learning may depend upon Wnt/ $\beta$-catenin signaling (Fujio et al. 2007; Maguschak and Ressler 2008; Dahlhoff et al. 2010). Interventions that inhibit $\beta$-catenin stabilization in the amygdala leave acquisition of fear memory intact, but interfere with consolidation (Maguschak and Ressler $2008,2011)$. However, rather than resulting in improved consolidation, increasing local Wnt availability throughout a learning session can also lead to memory deficits (Maguschak and Ressler 2011). These data suggest that the precise temporal regulation of various Wnt ligands, antagonists, and intracellular signaling partners may be crucial for generating new long-term memories. Indeed, Wnt signaling is dynamically regulated in the amygdala immediately after fear conditioning, with a large number of Wnt family ligands displaying transient changes in expression that normalize within hours after training (Maguschak and Ressler 2011). For instance, amygdala Wnt1 expression was found to be drastically reduced immediately after conditioning. Inhibiting this decrease via intra-amygdalar administration of exogenous Wnt1 immediately prior to fear conditioning resulted in significantly less freezing in response to the conditioned stimulus $48 \mathrm{~h}$ later. Conversely, when Wnt1 was administered after the point in time when endogenous Wnt1 levels decreased, mice displayed normal fear learning.

One possible explanation for these findings is that dynamic changes in Wnt signaling elicit both synaptic lability as well as synaptic stabilization (Figs. 2 and 3). In line with these findings, stabilization of $\beta$-catenin in the hippocampus was found to abolish LTD and result in impaired performance in spatial memory tasks by interfering with activity-dependent cadherin and AMPA receptor endocytosis at the synapse (Mills et al. 2014). Likewise, long-term retention of motor learning is impaired in mice lacking $\beta$-catenin in dopaminergic neurons (Diaz-Ruiz et al. 2012). 


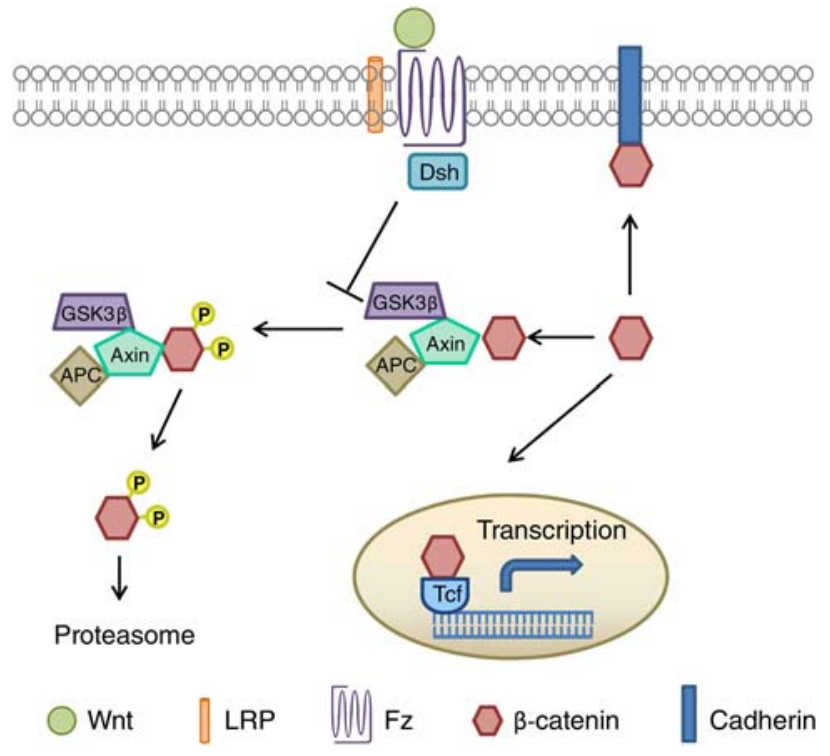

Figure 3. Proposed model for the regulation of synaptic restructuring by Wnt during learning (from Maguschak and Ressler 2011). (A) When extracellular Wnt is maintained at basal levels, the proteasomal degradation of $\beta$-catenin by Gsk-3 is inhibited, allowing $\beta$-catenin to stabilize cadherin at the synapse. During learning Wnt levels are transiently decreased, resulting in the destabilization and phosphorylation of $\beta$-catenin, which in turn destabilizes cadherin, temporarily rendering the synapse labile until basal Wnt levels are reinstated. (B) Inhibiting the recovery of Wnt signaling following the transient decrease that occurs during learning via, for instance, administration of the Wnt antagonist Dkk1, prevents reinitiation of the stable phase and impairs memory consolidation. (C) Inhibiting the transient decrease of Wnt during learning likewise inhibits consolidation, but does so by preventing destabilization of $\beta$-catenin and, thus, the initiation of the labile phase itself.

\section{Otx2}

As with both TLX and Wnt ligands, the highly conserved homeoprotein Otx2 is widely expressed during embryonic development and required for normal brain patterning, while it also has important functions in post-natal plasticity. The Otx2 gene encodes two protein isoforms that are identical in both mice and humans, and functionally indistinguishable in vitro (Beby and Lamonerie 2013). In mice, loss of Otx 2 results in severe malformation of the forebrain; in Drosophila and Xenopus, this impairment extends to truncation of the head and/or spinal cord itself, reflecting its crucial role in the regionalization of the central nervous system (Finkelstein et al. 1990; Pannese et al. 1995; Ang et al. 1996; Broccoli et al. 1999). Through its interactions with various downstream targets, Otx2 is further required for the generation of various neuronal subpopulations, including ocular motor and midbrain dopaminergic neurons (Tripathi et al. 2014; Sherf et al. 2015).

Three promoters are known to regulate Otx2 expression in mice, and all three are active in brain (Courtois et al. 2003). Notably, the proportion of the species of Otx2 mRNAs produced by various promoters changes over the course of differentiation, and in both retinal and embryonic stem cells, this shift is typified by decreased activity of the most proximal promoter in favor of increased activity of the most distal promoter (Courtois et al. 2003; Fossat et al. 2005). Otx 2 mRNA expression increases rapidly during early embryonic development before once more receding, reflecting the shifting functional roles of Otx2 across various developmental periods (Courtois et al. 2003). As embryonic, then fetal development progresses, expression of Otx 2 becomes more con- stricted and regionalized (for a detailed characterization, see Fossat et al. 2005). Although in mice Otx2 remains prominently expressed throughout the di- and mesencephalon, the cerebellum, and the choroid plexus during late embryonic stages, by the early post-natal period expression of Otx 2 mRNA within the brain is localized exclusively to the choroid plexus (Larsen et al. 2010; Spatazza et al. 2013). This pattern is similarly maintained in the developing human brain until at least 14 wk post-conception. However, recruitment of the homeoprotein itself to other brain regions continues to play an indispensable role in circuit development and maintenance as the organism matures (Fig. 1).

In contrast to its cell autonomous role as a transcription factor during early development, Otx2's regulation of post-natal plasticity is principally attributable to its function as a long-range signaling molecule that is best understood in the context of ocular dominance critical period plasticity. Briefly, in mammals, visual input from both eyes converge on common neurons within the visual cortex, yet neurons within this brain region are preferentially sensitive to input from one eye or the other. Hubel and Wiesel named this phenomenon "ocular dominance" and their subsequent work revealed that, for a brief window during development, suppressing visual input from one eye resulted in significant reorganization of the visual system: the power of each eye to elicit responses from downstream cortical neurons shifted in favor of the eye providing all of the visual input, whereas neurons in the visual cortex became less responsive to the occluded eye (Hubel and Wiesel 1962, 1970). This developmental window constitutes the ocular dominance critical period, and Otx2 earns its reputation as a master regulator of plasticity as a result of its central role in this phenomenon.

Following its translocation from the retina or secretion into the cerebrospinal fluid by choroid plexus cells, Otx 2 is internalized by cells in layers I, II/III, and IV of the post-natal visual cortex (Sugiyama et al. 2008; Spatazza et al. 2013; Kim et al. 2014). Transfer of Otx 2 protein, but not its synthesis in retinal cells, appears to be activity-dependent; whereas dark-rearing inhibited accumulation of Otx 2 protein in the visual cortex, transcription and translation of Otx2 in retinal cells was unaffected (Sugiyama et al. 2008). Work by Spatazza et al. (2013) suggests that Otx2 transfer from the choroid plexus to other brain regions via the cerebrospinal fluid is a passive process, and that the accumulation of Otx2 protein in target regions is regulated by the recipient cells.

Fast-spiking parvalbumin (PV)-expressing inhibitory neurons appear to be the primary, although not the exclusive, target of Otx2, and recruitment of Otx2 by PV-positive cells in the visual cortex regulates the onset and closure of the ocular dominance critical period (Sugiyama et al. 2008). In mice, this period of ocular dominance plasticity begins around post-natal day 21 , peaks $\sim 10 \mathrm{~d}$ later, and ends roughly $10 \mathrm{~d}$ after that (for a review of ocular dominance plasticity, see: Takesian and Hensch 2013), closely mirroring the development of perineuronal nets (PNNs) in the region (Ye and Miao 2013). This process is heavily dependent on sensory input, however, and interventions that reduce access to visual stimuli delay both the onset of the ocular dominance critical period and the maturation of PNNs. As PV neurons mature and the critical period progresses, the soma and processes of PV neurons in the visual cortex are gradually surrounded by PNNs: extracellular matrix enriched for glycosaminoglycans (Köppe et al. 1997; Sugiyama et al. 2008). Conversely, destruction of PNNs by chondroitinase ABC-mediated digestion of glycosaminoglycan side chains is sufficient to induce a resurgence of critical period-like plasticity among PV-positive neurons in the visual cortex and reinduce expression of other neuroplasticity-related genes (Pizzorusso et al. 2002, 2006; Bernard et al. 2016), as is interference of Otx2 binding to the chondroitin sulfates $\mathrm{D}$ and $\mathrm{E}$ contained within PNNs (Beurdeley et al. 2012; Depras et al. 2013). 


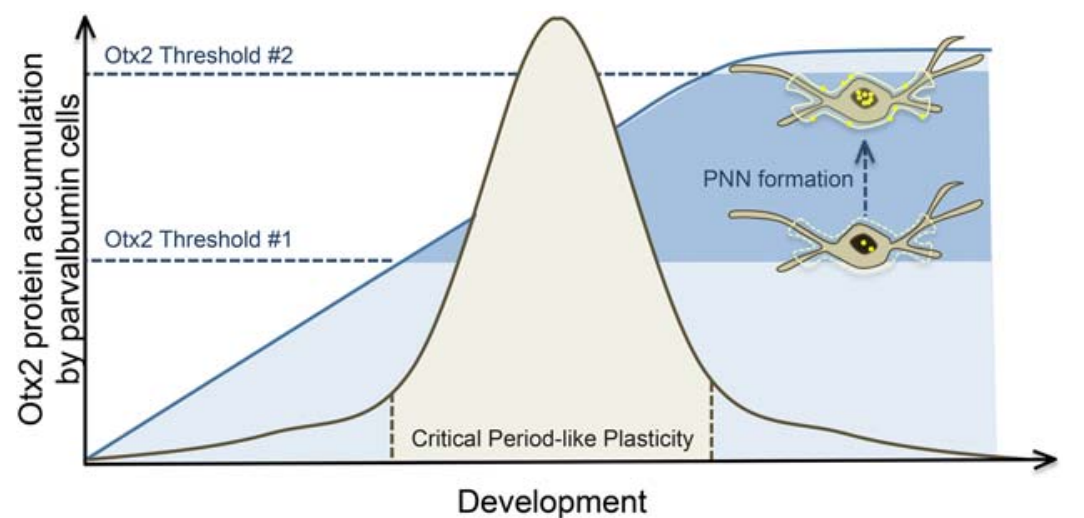

Figure 4. Post-natal Otx2 accumulation in parvalbumin-expressing interneurons and critical period plasticity. Initial sensory stimulation induces the formation of immature perineuronal nets (PNNs) around primarily parvalbumin-positive neurons, which in turn increase internalization of Otx2. Once Otx2 levels reach a certain threshold, critical period plasticity is initiated. Otx2 accumulation encourages the development and stabilization of PNNs, which in turn increase internalization of Otx2 around PNN-encapsulated cells. This positive feedback loop progresses until a second threshold is reached, and the critical period closes. From this point on, Otx2 internalization is maintained at a steady rate, as are mature PNNs, which together ensure that another phase of critical period-like plasticity is not initiated unless PNNs are destroyed, or Otx2 accumulation is inhibited.

The relationship between the transfer of Otx2 to PV cells and PNN formation is reciprocal rather than unidirectional, and although the composition of PNNs is crucial in regulating Otx2 binding, Otx2 in turn encourages and maintains PNN stabilization (Sugiyama et al. 2008; Depras et al. 2013; Spatazza et al. 2013). Thus, Otx2 functions as both a molecular trigger to induce the opening of critical period plasticity, as well as a brake that later closes this window of plasticity-a process that has been referred to as the "two threshold" model (Fig. 4; Spatazza et al. 2013; Takesian and Hensch 2013; Bernard and Prochiantz 2016). The specific means by which Otx 2 orchestrates these processes remain unclear, although several candidate mechanisms have been proposed including the transcriptional and/or epigenetic regulation of extracellular matrix protein expression, or of enzymes that digest such proteins by Otx2 (Bernard and Prochiantz 2016).

Although the first-and vast majority of-examinations of PNNs' role in adult neuroplasticity have been studies of the visual cortex, more recent explorations implicate PNNs in the stabilization of neural circuits throughout the brain, including prefrontal, somatosensory, and auditory cortex, as well as in the hippocampus, striatum, amygdala, and basal ganglia (Brückner et al. 2008; Balmer et al. 2009; Gogolla et al. 2009; Nowicka et al. 2009; Lee et al. 2012, 2017; Ohira et al. 2013; Spatazza et al. 2013; Yamada and Jinno 2013; Happel et al. 2014). Furthermore, although direct involvement of Otx2 has yet to be demonstrated in each of the brain regions mentioned above, widespread incorporation of choroid-plexus-derived Otx 2 in PV-expressing cells of the cingulate, somatosensory cortex, hippocampus, and basolateral amygdala is consistent with the hypothesis that this homeoprotein regulates PNN development throughout the brain (Spatazza et al. 2013). As is the case in visual cortex, PNN formation in the barrel cortex appears to be activity-dependent, suggesting that sensory input may be a universal requirement for PNN development throughout sensory cortical regions (McRae et al. 2007). It is less clear whether direct sensory input is required for PNN-mediated, critical period-like plasticity in limbic structures.

Before post-natal day 21, conditioned fear can be robustly and permanently extinguished in rodents by repeatedly exposing them to conditioned stimulus - that is, to the cue that was previously paired with an unconditioned aversive stimulus (Kim and
Richardson 2007a,b). In contrast, fear in adult animals is subject to renewal following extinction, a phenomenon wherein reexposure to the extinguished cue subsequently results in a reinstatement of freezing behavior. Interestingly, rather than displaying behavior that falls somewhere between that seen in young versus adult animals, adolescent rodents instead show adult-like fear conditioning and a marked impairment in fear extinction retention (Hefner and Holmes 2007; Kim et al. 2011). Age-related differences in contextual fear memory have also been reported, with adolescent animals displaying more robust contextual extinction than either very young or adult animals (Pattwell et al. 2011, 2016). This fluctuation in the efficiency of fearrelated learning has been suggested to result from differences in the development of neural circuits underlying conditioning and extinction (Pattwell et al. 2016). Ensuing changes in local excitatory/ inhibitory balance (Baker et al. 2016), and the course of Otx2 accumulation and PNN maturation around PV interneurons in the BLA provides a tentative mechanism for the emergence of this pattern. The most rapid period of PNN formation in the murine BLA occurs between post-natal day 16 and 23, and digestion of PNNs in animals over 3 wk of age with chondroitinase $\mathrm{ABC}$ inhibits the extinction retrieval that is typically observed during later developmental stages (Gogolla et al. 2009). In keeping with this, depletion of PNNs in the BLA following extinction also impairs the resurgence of priming-induced conditioned place preference among morphineor cocaine-conditioned animals (Xue et al. 2014). Thus, the stabilization of PNNs in learning centers may underlie the shift from malleable to resilient memory storage in these brains structures. Maintaining this stabilized state, in turn, appears to require continuous, brain-wide access to non-cell-autonomous Otx2 protein (Spatazza et al. 2013; Prochiantz et al. 2014).

\section{Discussion}

The three "master regulators" of adult brain plasticity reviewed above are notable for their distinct contributions to neural remodeling, as well as their differing patterns of expression over the course of development. As such, their functions and temporal distributions may be characterized according to several characteristics. For instance, whereas TLX's contributions to neuroplasticity appear stable over the course of development, the same cannot be said for either Wnts or Otx2. From embryonic development through adulthood, TLX remains a key regulator of cell proliferation and fate; its distribution changes, with its expression narrowing to remain within the borders of whatever brain regions retain neurogenic potential at any given time. In contrast, Otx 2 begins life as a transcription factor that instructs regionalization of the head and central nervous system, and later adopts a new role as a key orchestrator of PNN formation. Wnt signaling likewise plays a role in regional specification and differentiation during development, and in adulthood remains widely expressed, retaining some of its early capabilities, losing others, and expanding its repertoire to include the fine-tuning of synaptic contacts. While TLX is a functional unitasker, Otx2 and Wnts are multitaskers. 
Similarly, we may instead divide these three regulators according to whether they mediate regionally localized and specific forms of plasticity, or the same neuroplastic processes in all brain regions. Whereas Wnt signaling has been implicated in multiple processes in myriad cell types across the entire mature brain, TLX expression is limited to neurogenic niches during adulthood, and post-natal Otx 2 protein accumulates in multiple brain regions, but is preferentially sequestered around parvalbumin-expressing interneurons. Notably, in the case of Otx 2 , the site of its production is also greatly narrowed post-natally, and although this homeoprotein is carried to distal brain regions in cerebral spinal fluid, Otx2 mRNA expression is limited to the choroid plexus after birth (Fig. 1). TLX, Otx2, and Wnts thus also differ fundamentally in terms of how constricted their actions are, vis a vis their site of production. Otx2 proteins circulate broadly whereas Wnts are more restricted, albeit as secreted ligands they act both pre- and postsynaptically. TLX appears to act in a strictly cell autonomous manner.

The distinct temporal and regional expression profiles of the genes discussed above may further provide clues as to their utility as therapeutic targets in the treatment of fear- and stress-related disorders. The apparent genetic heterogeneity of conferred psychiatric risk, and the sheer variety of pathways whose malfunction may lead to the same general phenotype suggests that directly correcting any specific impairment in gene function is unlikely to be effective, or even feasible, for large swaths of the clinical populations in question. In other words, although reversing the cause of a disorder may be ideal, it may not be actionable. The best course may instead prove to be a return to an earlier approach: identifying molecular drug targets whose expression and function is not commonly altered by stress or illness, but whose manipulation is nevertheless capable of shifting systems of plasticity in the desired direction as a means of compensating for the underlying impairment.

This approach carries its own set of limitations, of course, among them the potential for functionally off-target effects. When evaluating the suitability of "master regulators" as drug targets, those whose expression are limited to relatively few brain regions or cell populations are therefore likely preferable to those whose roles are more varied or widespread. From a temporal standpoint, changes in the distribution of expression of such regulators over time may likewise be used as a means of physically restricting the actions of interventions designed to interact with these molecules. The substantial post-natal restriction of TLX expression to neurogenic brain regions, like the hippocampus for instance, may thus provide a means of pharmacologically targeting both distinct neuroplastic processes and specific brain regions among clinical populations with depression or anxiety disorders. Similarly, the fine tuned temporal activation of experiencedependent Wnt signaling during learning may in turn provide a means of restricting the regional influence of Wnt-targeting pharmacological interventions. Combined with behavioral interventions designed to elicit synaptic destabilization in specific neural circuits, acute rather than chronic administration of Wnt pathway modulators could facilitate remodeling in a more restricted fashion than would be achieved with pharmacotherapy alone, and thereby reduce the incidence of undesirable side effects. Still other psychiatric disorders are associated with cell-type specific impairments spread across multiple cortical regions, such as schizophrenia, in which the function of parvalbumin neurons is altered (Lewis et al. 2012). Otx2's localization to parvalbumin-expressing interneurons may likewise provide a means of resetting the excitatory-inhibitory balance of neural circuits in which parvalbumin interneurons have developed abnormally, without directly altering the function or connectivity of other GABAergic neuronal subtypes.

It is nevertheless crucial to consider the potentially negative ramifications of pharmacologically or genetically reinitiating levels or forms of plasticity that otherwise would not naturally occur. Whereas TLX- and Wnt-mediated neuroplasticity are modulated bidirectionally in the adult brain as a result of environmental factors, reopening critical period plasticity through the dissolution of perineuronal nets is not. Such a reversal of structural features that are ordinarily fixed during development could result in wide-ranging repercussions in both local and long-range signaling. Given the extent to which Otx2 accumulation by parvalbuminexpressing neurons appears to alter environmental processing and learning (Hefner and Holmes 2007; Kim et al. 2011; Ye and Miao 2013), attempts to manipulate critical period-like plasticity would necessarily need to be approached with the utmost caution.

It is clear that progress in the treatment of both neuropsychiatric disorders and somatic illnesses is being made on converging fronts, and therapeutic approaches used in one field may be repurposed to great effect. For instance, TLX's ability to suppress senescence in tumors was recently reported to be mediated by its regulation of CDNKN1A and SIRT1, both of which have been implicated in the regulation of neurogenesis in turn (Chesnokova and Pechnick 2008; Wu et al. 2015; Kim et al. 2016). Despite early characterization as a ligand-independent receptor, TLX possesses a noncanonical ligand-binding domain that retains the potential to form a ligand binding pocket, and thus far three compounds have been identified that can bind to and potentiate TLX's repressive transcriptional signaling (Benod et al. 2014). Although enhancing TLX function may exacerbate cancer-related suppression of senescence in tumor cells, such drugs may provide a direct and specific means of enhancing neurogenesis without altering other plasticity-related signaling outside of the human neurogenic zones.

In summary, we have reviewed the developmental, neurogenic, and potential roles in adult synaptic plasticity of three gene pathways related to fear- and stress-related processing, TLX, Wnts, and Otx2. Though these are active in different locations and at different times in brain development and adult cellular function, they all serve as master regulators of neural development and plasticity, and thus may serve as important and potentially powerful targets for intervention. Furthermore, particularly in the oncology field, approaches targeting such developmental oncogene-related functions have led to the development of new potential pharmacotherapies. Understanding how developmental processes are recapitulated during adult plasticity remains an interesting and potentially fruitful way of understanding the biology of, and new treatment approaches for, psychiatric disorders involving learning, memory, and neural plasticity.

\section{Acknowledgments}

M.E.M. is supported by a fellowship from the Canadian Institutes of Health Research. Support was also provided by the American Heart Association, AHA Award \#15CSA2430001 and the National Institutes of Health, MH108665, MH110441, MH100122, and HD088931.

\section{References}

Adachi K, Mirzadeh Z, Sakaguchi M, Yamashita T, Nikolcheva T, Gotoh Y, Peltz G, Gong L, Kawase T, Alvarez-Buylla A, et al. 2007. $\beta$-Catenin signaling promotes proliferation of progenitor cells in the adult mouse subventricular zone. Stem Cells 25: 2827-2836.

Allen Institute for Brain Science. 2004. Allen mouse brain atlas. Available from: mouse.brain-map.org.

Andersson ER, Saltó C, Villaescusa JC, Cajanek L, Yang S, Bryjova L, Nagy II, Vainio SJ, Ramirez C, Bryja V, et al. 2013. Wnt5a cooperates with canonical Wnts to generate midbrain dopaminergic neurons in vivo and in stem cells. Proc Natl Acad Sci 110: E602-E610.

Ang SL, Jin O, Rhinn M, Daigle N, Stevenson L, Rossant J. 1996. A targeted mouse Otx2 mutation leads to severe defects in gastrulation and 
formation of axial mesoderm and to deletion of rostral brain. Development 122: 243-252.

Baker KD, Bisby MA, Richardson R. 2016. Impaired fear extinction in adolescent rodents: behavioural and neural analyses. Neurosci Biobehav Rev 70: $59-73$.

Balmer TS, Carels VM, Frisch JL, Nick TA. 2009. Modulation of perineuronal nets and parvalbumin with developmental song learning. J Neurosci 29: $12878-12885$

Banerjee SB, Morrison FG, Ressler KJ. 2017. Genetic approaches for the study of PTSD: advances and challenges. Neurosci Lett 649: 139-146.

Beby F, Lamonerie T. 2013. The homeobox gene Otx2 in development and disease. Exp Eye Res 111: 9-16.

Benod C, Villagomez R, Filgueira CS, Hwang PK, Leonard PG, Poncet-Montange G, Rajagopalan S, Fletterick RJ, Gustafsson JÅ, Webb P. 2014. The human orphan nuclear receptor tailless (TLX, NR2E1) is druggable. PLoS One 9: e99440.

Bernard C, Prochiantz A. 2016. Otx2-PNN interaction to regulate cortical plasticity. Neural Plast 2016: 7931693.

Bernard C, Vincent C, Testa D, Bertini E, Ribot J, Di Nardo AA, Volovitch M, Prochiantz A. 2016. A mouse model for conditional secretion of specific single-chain antibodies provides genetic evidence for regulation of cortical plasticity by a non-cell autonomous homeoprotein transcription factor. PLoS Genet 12: e1006035.

Besnard A, Sahay A. 2016. Adult hippocampal neurogenesis, fear generalization, and stress. Neuropsychopharmacology 41: 24-44.

Beurdeley M, Spatazza J, Lee HH, Sugiyama S, Bernard C, Di Nardo AA Hensch TK, Prochiantz A. 2012. Otx2 binding to perineuronal nets persistently regulates plasticity in the mature visual cortex. J Neurosci 32: 9429-9237.

Broccoli V, Boncinelli E, Wurst W. 1999. The caudal limit of Otx2 expression positions the isthmic organizer. Nature 401: 164-168.

Brückner G, Morawski M, Arendt T. 2008. Aggrecan-based extracellular matrix is an integral part of the human basal ganglia circuit. Neuroscience 151: $489-504$.

Callaghan BL, Tottenham N. 2016. The neuro-environmental loop of plasticity: a cross-species analysis of parental effects on emotion circuitry development following typical and adverse caregiving. Neuropsychopharmacology 41: 163-176.

Chenn A, Walsh CA. 2002. Regulation of cerebral cortical size by control of cell cycle exit in neural precursors. Science 297: 365-369.

Chesnokova V, Pechnick RN. 2008. Antidepressants and Cdk inhibitors: releasing the brake on neurogenesis. Cell Cycle 7: 2321-2326.

Christie BR, Li AM, Redila VA, Booth H, Wong BK, Eadie BD, Ernst C, Simpson EM. 2006. Deletion of the nuclear receptor Nr2e1 impairs synaptic plasticity and dendritic structure in the mouse dentate gyrus. Neuroscience 137: 1031-1037.

Courtois V, Chatelain G, Han ZY, Le Novère N, Brun G, Lamonerie T. 2003. New Otx2 mRNA isoforms expressed in the mouse brain. J Neurochem 84 : 840-853.

Dahlhoff M, Siegmund A, Golub Y, Wolf E, Holsboer F, Wotjak CT. 2010. AKT/GSK-3 $\beta / \beta$-catenin signalling within hippocampus and amygdala reflects genetically determined differences in posttraumatic stress disorder like symptoms. Neuroscience 169: 1216-1226.

Depras G, Bernard C, Perrot A, Cattiaux L, Prochiantz A, Lortat-Jacob H, Mallet JM. 2013. Toward libraries of biotinylated chondroitin sulfate analogues: from synthesis to in vivo studies. Chemistry 19: 531-540.

Diaz-Ruiz O, Zhang Y, Shan L, Malik N, Hoffman AF, Ladenheim B, Cadet JL, Lupica CR, Tagliaferro A, Brusco A, et al. 2012. Attenuated response to methamphetamine sensitization and deficits in motor learning and memory after selective deletion of $\beta$-catenin in dopamine neurons. Learn Mem 19: 341-350.

Ehrlich DE, Josselyn SA. 2016. Plasticity-related genes in brain development and amygdala-dependent learning. Genes Brain Behav 15: 125-143.

Elmi M, Matsumoto Y, Zeng ZJ, Lakshminarasimhan P, Yang W, Uemura A, Nishikawa S, Moshiri A, Tajima N, Agren H, et al. 2010. TLX activates MASH1 for induction of neuronal lineage commitment of adult hippocampal neuroprogenitors. Mol Cell Neurosci 45: 121-131.

Farzanehfar P, Lu SS, Dey A, Musiienko D, Baagil H, Horne MK, Aumann TD. 2017. Evidence of functional duplicity of Nestin expression in the adult mouse midbrain. Stem Cell Res 19: 82-93.

Finkelstein R, Smouse D, Capaci TM, Spradling AC, Perrimon N. 1990. The orthodenticle gene encodes a novel homeo domain protein involved in the development of the Drosophila nervous system and ocellar visual structures. Genes Dev 4: 1516-1527.

Fioravante D, Regehr WG. 2011. Short-term forms of presynaptic plasticity. Curr Opin Neurobiol 21: 269-274.

Fortress AM, Schram SL, Tuscher JJ, Frick KM. 2013. Canonical Wnt signaling is necessary for object recognition memory consolidation. I Neurosci 33: 12619-12626.

Fossat N, Courtois V, Chatelain G, Brun G, Lamonerie T. 2005. Alternative usage of Otx2 promoters during mouse development. Dev Dyn 233: 154-160.
Fossat N, Le Greneur C, Béby F, Vincent S, Godement P, Chatelain G, Lamonerie T. 2007. A new GFP-tagged line reveals unexpected Otx2 protein localization in retinal photoreceptors. BMC Dev Biol 7: 122.

Fujio J, Hosono H, Ishiguro K, Ikegami S, Fujita SC. 2007. Tau phosphorylation in the mouse brain during aversive conditioning. Neurochem Int 51: 200-208.

Glinka A, Wu W, Delius H, Monaghan AP, Blumenstock C, Niehrs C. 1998. Dickkopf-1 is a member of a new family of secreted proteins and functions in head induction. Nature 391: 357-362.

Gogolla N, Caroni P, Lüthi A, Herry C. 2009. Perineuronal nets protect fear memories from erasure. Science 325: 1258-1261.

Gonçalves JT, Schafer ST, Gage FH. 2016. Adult neurogenesis in the hippocampus: from stem cells to behavior. Cell 167: 897-914.

Guirado R, Perez-Rando M, Sanchez-Matarredona D, Castillo-Gómez E, Liberia T, Rovira-Esteban L, Varea E, Crespo C, Blasco-Ibáñez JM, Nacher J. 2014. The dendritic spines of interneurons are dynamic structures influenced by PSA-NCAM expression. Cereb Cortex 24: 3014-3024.

Habas R, Dawid IB. 2005. Dishevelled and Wnt signaling: is the nucleus the final frontier? J Biol 4: 2 .

Happel MF, Niekisch H, Castiblanco Rivera LL, Ohl FW, Deliano M, Frischknecht R. 2014. Enhanced cognitive flexibility in reversal learning induced by removal of the extracellular matrix in auditory cortex. Proc Natl Acad Sci 111: 2800-2805.

Hefner K, Holmes A. 2007. Ontogeny of fear-, anxiety- and depression-related behavior across adolescence in C57BL/6J mice. Behav Brain Res 176: 210-215.

Hirabayashi $Y$, Itoh Y, Tabata H, Nakajima K, Akiyama T, Masuyama N, Gotoh Y. 2004. The Wnt/ $\beta$-catenin pathway directs neuronal differentiation of cortical neural precursor cells. Development 131: 2791-2801.

Huang Y, Liu X, Wang Y. 2015. MicroRNA-378 regulates neural stem cell proliferation and differentiation in vitro by modulating Tailless expression. Biochem Biophys Res Commun 466: 214-220.

Hubel DH, Wiesel TN. 1962. Receptive fields, binocular interaction and functional architecture in the cat's visual cortex. J Physiol 160: 106-154.

Hubel DH, Wiesel TN. 1970. The period of susceptibility to the physiological effects of unilateral eye closure in kittens. J Physiol 206: 419-436.

Inestrosa NC, Arenas E. 2010. Emerging roles of Wnts in the adult nervous system. Nat Rev Neurosci 11: 77-86.

Islam MM, Zhang C-L. 2015. TLX: a master regulator for neural stem cell maintenance and neurogenesis. Biochim Biophys Acta 1849: 210-216.

Israsena N, Hu M, Fu W, Kan L, Kessler JA. 2004. The presence of FGF2 signaling determines whether $\beta$-catenin exerts effects on proliferation or neuronal differentiation of neural stem cells. Dev Biol 268: 220-231.

Jang MH, Bonaguidi MA, Kitabatake Y, Sun J, Song J, Kang E, Jun H, Zhong C, Su Y, Guo JU, et al. 2013. Secreted frizzled-related protein 3 regulates activity-dependent adult hippocampal neurogenesis. Cell Stem Cell 12: 215-223.

Kiecker C, Niehrs C. 2001. A morphogen gradient of Wnt/ $\beta$-catenin signalling regulates anteroposterior neural patterning in Xenopus. Development 128: 4189-4201.

Kilaru V, Iyer SV, Almli LM, Stevens JS, Lori A, Jovanovic T, Ely TD, Bradley B, Binder EB, Koen N, et al. 2016. Genome-wide gene-based analysis suggests an association between Neuroligin 1 (NLGN1) and post-traumatic stress disorder. Transl Psychiatry 6: e820.

Kim JH, Richardson R. 2007a. A developmental dissociation of context and GABA effects on extinguished fear in rats. Behav Neurosci 121: 131-139.

Kim JH, Richardson R. 2007b. A developmental dissociation in reinstatement of an extinguished fear response in rats. Neurobiol Learn Mem 88: $48-57$

Kim JH, Li S, Richardson R. 2011. Immunohistochemical analyses of long-term extinction of conditioned fear in adolescent rats. Cereb Cortex 21: $530-538$

Kim N, Acampora D, Dingli F, Loew D, Simeone A, Prochiantz A, Di Nardo AA. 2014. Immunoprecipitation and mass spectrometry identify non-cell autonomous Otx2 homeoprotein in the granular and supragranular layers of mouse visual cortex. F100ORes 3: 178 .

Kim BS, Lee CH, Chang GE, Cheong E, Shin I. 2016. A potent and selective small molecule inhibitor of sirtuin 1 promotes differentiation of pluripotent P19 cells into functional neurons. Sci Rep 6: 34324.

Komiya Y, Habas R. 2008. Wnt signal transduction pathways. Organogenesis 4: $68-75$.

Köppe G, Brückner G, Brauer K, Härtig W, Bigl V. 1997. Developmental patterns of proteoglycan-containing extracellular matrix in perineuronal nets and neuropil of the postnatal rat brain. Cell Tissue Res 288: $33-41$

Kuwabara T, Hsieh J, Muotri A, Yeo G, Warashina M, Lie DC, Moore L, Nakashima K, Asashima M, Gage FH. 2009. Wnt-mediated activation of NeuroD1 and retro-elements during adult neurogenesis. Nat Neurosci 12: 1097-1105. 
Land PW, Monaghan AP. 2003. Expression of the transcription factor, tailless, is required for formation of superficial cortical layers. Cereb Cortex 13: 921-931.

Larsen KB, Lutterodt MC, Møllgård K, Møller M. 2010. Expression of the homeobox genes OTX2 and OTX1 in the early developing human brain. J Histochem Cytochem 58: 669-678.

Lee SM, Tole S, Grove E, McMahon AP. 2000. A local Wnt-3a signal is required for development of the mammalian hippocampus. Development 127: 457-467.

Lee H, Leamey CA, Sawatari A. 2012. Perineuronal nets play a role in regulating striatal function in the mouse. PLoS One 7: e32747.

Lee HH, Bernard C, Ye Z, Acampora D, Simeone A, Prochiantz A, Di Nardo AA, Hensch TK. 2017. Genetic Otx2 mis-localization delays critical period plasticity across brain regions. Mol Psychiatry 22: 680-688.

Lein ES, Hawrylycz MJ, Ao N, Ayres M, Bensinger A, Bernard A, Boe AF, Boguski MS, Brockway KS, Byrnes EJ, et al. 2007. Genome-wide atlas of gene expression in the adult mouse brain. Nature 445: 168-176.

Lewis DA, Curley AA, Glausier JR, Volk DW. 2012. Cortical parvalbumin interneurons and cognitive dysfunction in schizophrenia. Trends Neurosci 35: 57-67.

Li W, Sun G, Yang S, Qu Q, Nakashima K, Shi Y. 2008. Nuclear receptor TLX regulates cell cycle progression in neural stem cells of the developing brain. Mol Endocrinol 22: 56-64.

Li W, Sun G, Murai K, Ye P, Shi Y. 2012. Characterization of TLX expression in neural stem cells and progenitor cells in adult brains. PLoS One 7: e43324.

Lie D-C, Colamarino SA, Song H-J, Désiré L, Mira H, Consiglio A, Lein ES, Jessberger S, Lansford H, Dearie AR, et al. 2005. Wnt signalling regulates adult hippocampal neurogenesis. Nature 437: 1370-1375.

Liu HK, Belz T, Bock D, Takacs A, Wu H, Lichter P, Chai M, Schütz G. 2008. The nuclear receptor tailless is required for neurogenesis in the adult subventricular zone. Genes Dev 22: 2473-2478.

Machon O, Backman M, Machonova O, Kozmik Z, Vacik T, Andersen L, Krauss S. 2007. A dynamic gradient of Wnt signaling controls initiation of neurogenesis in the mammalian cortex and cellular specification in the hippocampus. Dev Biol 311: 223-237.

Maguschak KA, Ressler KJ. 2008. $\beta$-Catenin is required for memory consolidation. Nat Neurosci 11: 1319-1326.

Maguschak KA, Ressler KJ. 2011. Wnt signaling in amygdala-dependent learning and memory. J Neurosci 31: 13057-13067.

Maguschak KA, Ressler KJ. 2012. A role for Wnt/B-catenin signaling in the neural mechanisms of behavior. J Neuroimmune Pharmacol 7: 763-773.

Mani P, Jarrell A, Myers J, Atit R. 2010. Visualizing canonical Wnt signaling during mouse craniofacial development. Dev Dyn 239: 354-363.

McEwen BS, Eiland L, Hunter RG, Miller MM. 2012. Stress and anxiety: structural plasticity and epigenetic regulation as a consequence of stress. Neuropharmacology 62: 3-12.

McRae PA, Rocco MM, Kelly G, Brumberg JC, Matthews RT. 2007. Sensory deprivation alters aggrecan and perineuronal net expression in the mouse barrel cortex. J Neurosci 27: 5405-5413.

Megason SG, McMahon AP. 2002. A mitogen gradient of dorsal midline Wnts organizes growth in the CNS. Development 129: 2087-2098.

Mills F, Bartlett TE, Dissing-Olesen L, Wisniewska MB, Kuznicki J, Macvicar BA, Wang YT, Bamji SX. 2014. Cognitive flexibility and long-term depression (LTD) are impaired following $\beta$-catenin stabilization in vivo. Proc Natl Acad Sci 111: 8631-8636.

Monaghan AP, Grau E, Bock D, Schütz G. 1995. The mouse homolog of the orphan nuclear receptor tailless is expressed in the developing forebrain. Development 121: 839-853.

Monuki ES, Porter FD, Walsh CA. 2001. Patterning of the dorsal telencephalon and cerebral cortex by a roof plate-Lhx2 pathway. Neuron 32: 591-604.

Munji RN, Choe Y, Li G, Siegenthaler JA, Pleasure SJ. 2011. Wnt signaling regulates neuronal differentiation of cortical intermediate progenitors. J Neurosci 31: 1676-1687.

Murai K, Sun G, Ye P, Tian E, Yang S, Cui Q, Sun G, Trinh D, Sun O, Hong T, et al. 2016. The TLX-miR-219 cascade regulates neural stem cell proliferation in neurodevelopment and schizophrenia iPSC model. Nat Commun 7: 10965

Mutch CA, Schulte JD, Olson E, Chenn A. 2010. $\beta$-Catenin signaling negatively regulates intermediate progenitor population numbers in the developing cortex. PLoS One 5: e12376.

Ni N, Zhang D, Xie Q, Chen J, Wang Z, Deng Y, Wen X, Zhu M, Ji J, Fan X, et al. 2014. Effects of let-7b and TLX on the proliferation and differentiation of retinal progenitor cells in vitro. Sci Rep 4: 6671 .

Nishimura M, Naito S, Yokoi T. 2004. Tissue-specific mRNA expression profiles of human nuclear receptor subfamilies. Drug Metab Pharmacokinet 19: 135-149.

Niu W, Zou Y, Shen C, Zhang C-L. 2011. Activation of postnatal neural stem cells requires nuclear receptor TLX. J Neurosci 31: 13816-13828.

Nowicka D, Soulsby S, Skangiel-Kramska J, Glazewski S. 2009. Parvalbumin-containing neurons, perineuronal nets and experience-dependent plasticity in murine barrel cortex. Eur J Neurosci 30: $2053-2063$.

Obernier K, Simeonova I, Fila T, Mandl C, Hölzl-Wenig G,

Monaghan-Nichols P, Ciccolini F. 2011. Expression of Tlx in both stem cells and transit amplifying progenitors regulates stem cell activation and differentiation in the neonatal lateral subependymal zone. Stem Cells 29: 1415-1426.

Ohira K, Takeuchi R, Iwanaga T, Miyakawa T. 2013. Chronic fluoxetine treatment reduces parvalbumin expression and perineuronal nets in $\gamma$-aminobutyric acidergic interneurons of the frontal cortex in adult mice. Mol Brain 6: 43.

O'Loghlen A, Martin N, Krusche B, Pemberton H, Alonso MM, Chandler H, Brookes S, Parrinello S, Peters G, Gil J. 2015. The nuclear receptor NR2E1/TLX controls senescence. Oncogene 34: 4069-4077.

Pannese M, Polo C, Andreazzoli M, Vignali R, Kablar B, Barsacchi G, Boncinelli E. 1995. The Xenopus homologue of Otx2 is a maternal homeobox gene that demarcates and specifies anterior body regions. Development 121: 707-720.

Pattwell SS, Bath KG, Casey BJ, Ninan I, Lee FS. 2011. Selective early-acquired fear memories undergo temporary suppression during adolescence. Proc Natl Acad Sci 108: 1182-1187.

Pattwell SS, Liston C, Jing D, Ninan I, Yang RR, Witztum J, Murdock MH, Dincheva I, Bath KG, Casey BJ, et al. 2016. Dynamic changes in neura circuitry during adolescence are associated with persistent attenuation of fear memories. Nat Commun 7: 11475 .

Pérez-Domper P, Palomo V, Gradari S, Gil C, de Ceballos ML, Martínez A, Trejo JL. 2017. The GSK-3-inhibitor VP2.51 produces antidepressant effects associated with adult hippocampal neurogenesis. Neuropharmacology 116: 174-187.

Pizzorusso T, Medini P, Berardi N, Chierzi S, Fawcett JW, Maffei L. 2002. Reactivation of ocular dominance plasticity in the adult visual cortex. Science 298: 1248-1251.

Pizzorusso T, Medini P, Landi S, Baldini S, Berardi N, Maffei L. 2006. Structural and functional recovery from early monocular deprivation in adult rats. Proc Natl Acad Sci 103: 8517-8522.

Prochiantz A, Fuchs J, Di Nardo AA. 2014. Postnatal signalling with homeoprotein transcription factors. Philos Trans R Soc Lond B Biol Sci 369: 20130518

Qin S, Niu W, Iqbal N, Smith DK, Zhang CL. 2014. Orphan nuclear receptor TLX regulates astrogenesis by modulating BMP signaling. Front Neurosci 8: 74 .

Qu Q, Sun G, Li W, Yang S, Ye P, Zhao C, Yu RT, Gage FH, Evans RM, Shi Y. 2010. Orphan nuclear receptor TLX activates Wnt/ $\beta$-catenin signalling to stimulate neural stem cell proliferation and self-renewal. Nat Cell Biol 12: $31-40$

Roy K, Thiels E, Monaghan AP. 2002. Loss of the tailless gene affects forebrain development and emotional behavior. Physiol Behav 77: 595-600.

Roy K, Kuznicki K, Wu Q, Sun Z, Bock D, Schutz G, Vranich N, Monaghan AP. 2004. The Tlx gene regulates the timing of neurogenesis in the cortex. J Neurosci 24: 8333-8345.

Ryan SM, O'Keeffe GW, O'Connor C, Keeshan K, Nolan YM. 2013. Negative regulation of TLX by IL-1 $\beta$ correlates with an inhibition of adult hippocampal neural precursor cell proliferation. Brain Behav Immun 33: 7-13.

Sato C, Hane M, Kitajima K. 2016. Relationship between ST8SIA2, polysialic acid and its binding molecules, and psychiatric disorders. Biochim Biophys Acta 1860: 1739-1752.

Schafer ST, Han J, Pena M, von Bohlen Und Halbach O, Peters J, Gage FH. 2015. The Wnt adaptor protein ATP6AP2 regulates multiple stages of adult hippocampal neurogenesis. J Neurosci 35: 4983-4998.

Seib DR, Corsini NS, Ellwanger K, Plaas C, Mateos A, Pitzer C, Niehrs C, Celikel T, Martin-Villalba A. 2013. Loss of Dickkopf-1 restores neurogenesis in old age and counteracts cognitive decline. Cell Stem Cell 12: 204-214.

Seo DO, Carillo MA, Chih-Hsiung Lim S, Tanaka KF, Drew MR. 2015. Adult hippocampal neurogenesis modulates fear learning through associative and nonassociative mechanisms. J Neurosci 35: 11330-11345.

Sherf O, Nashelsky Zolotov L, Liser K, Tilleman H, Jovanovic VM, Zega K, Jukic MM, Brodski C. 2015. Otx2 requires $L m x 1 b$ to control the development of mesodiencephalic dopaminergic neurons. PLoS One 10: e0139697.

Shi Y, Chichung Lie D, Taupin P, Nakashima K, Ray J, Yu RT, Gage FH, Evans RM. 2004. Expression and function of orphan nuclear receptor TLX in adult neural stem cells. Nature 427: 78-83.

Smoller JW. 2016. The genetics of stress-related disorders: PTSD, depression, and anxiety disorders. Neuropsychopharmacology 41: 297-319.

Spatazza J, Lee HH, Di Nardo AA, Tibaldi L, Joliot A, Hensch TK, Prochiantz A. 2013. Choroid-plexus-derived Otx2 homeoprotein constrains adult cortical plasticity. Cell Rep 3: 1815-1823. 
Sugiyama S, Di Nardo AA, Aizawa S, Matsuo I, Volovitch M, Prochiantz A, Hensch TK. 2008. Experience-dependent transfer of Otx2 homeoprotein into the visual cortex activates postnatal plasticity. Cell 134: 508-520.

Sun G, Yu RT, Evans RM, Shi Y. 2007. Orphan nuclear receptor TLX recruits histone deacetylases to repress transcription and regulate neural stem cell proliferation. Proc Natl Acad Sci 104: 15282-15287.

Sweatt JD. 2016. Neural plasticity and behavior - sixty years of conceptual advances. J Neurochem 139(Suppl 2): 179-199.

Takesian AE, Hensch TK. 2013. Balancing plasticity/stability across brain development. Prog Brain Res 207: 3-34.

Thompson CL, Ng L, Menon V, Martinez S, Lee CK, Glattfelder K, Sunkin SM, Henry A, Lau C, Dang C, et al. 2014. A high-resolution spatiotemporal atlas of gene expression of the developing mouse brain. Neuron 83: 309-323.

Tripathi PP, Di Giovannantonio LG, Sanguinetti E, Acampora D, Allegra M, Caleo M, Wurst W, Simeone A, Bozzi Y. 2014. Increased dopaminergic innervation in the brain of conditional mutant mice overexpressing Otx2: effects on locomotor behavior and seizure susceptibility. Neuroscience 261: 173-183.

van Amerongen R, Mikels A, Nusse R. 2008. Alternative wnt signaling is initiated by distinct receptors. Sci Signal 1: re9.

Varela-Nallar L, Inestrosa NC. 2013. Wnt signaling in the regulation of adult hippocampal neurogenesis. Front Cell Neursci 7: 100.

Wu D, Yu S, Jia L, Zou C, Xu Z, Xiao L, Wong KB, Ng CF, Chan FL. 2015. Orphan nuclear receptor TLX functions as a potent suppressor of oncogene-induced senescence in prostate cancer via its transcriptional co-regulation of the CDKN1A (p21(WAF1) (/) (CIP1)) and SIRT1 genes. I Pathol 236: 103-115.

Xie T, Stathopoulou MG, de Andrès F, Siest G, Murray H, Martin M, Cobaleda J, Delgado A, Lamont J, Peñas-Lledó E, et al. 2017.
VEGF-related polymorphisms identified by GWAS and risk for major depression. Transl Psychiatry 7: e1055.

Xu N, Zhou WJ, Wang Y, Huang SH, Li X, Chen ZY. 2015. Hippocampal Wnt3a is necessary and sufficient for contextual fear memory acquisition and consolidation. Cereb Cortex 25: 4062-4075.

Xue YX, Xue LF, Liu JF, He J, Deng JH, Sun SC, Han HB, Luo YX, Xu LZ, Wu P, et al. 2014. Depletion of perineuronal nets in the amygdala to enhance the erasure of drug memories. J Neurosci 34: 6647-6658.

Yamada J, Jinno S. 2013. Spatio-temporal differences in perineuronal net expression in the mouse hippocampus, with reference to parvalbumin. Neuroscience 253: 368-379.

Ye Q, Miao QL. 2013. Experience-dependent development of perineuronal nets and chondroitin sulfate proteoglycan receptors in mouse visual cortex. Matrix Biol 32: 352-363.

Young KA, Berry ML, Mahaffrey CL, Saionz JR, Hawes NL, Chang B, Zheng QY, Smith RS, Bronson RT, Nelson RJ, et al. 2002. Fierce: a new mouse deletion of Nr2e1; violent behaviour and ocular abnormalities are background-dependent. Behav Brain Res 132: 145-158.

Yu RT, McKeown M, Evans RM, Umesono K. 1994. Relationship between Drosophila gap gene tailless and a vertebrate nuclear receptor Tlx. Nature 370: $375-379$.

Zhang CL, Zou Y, He W, Gage FH, Evans RM. 2008. A role for adult TLX-positive neural stem cells in learning and behaviour. Nature 451: 1004-1007.

Zhao C, Sun G, Ye P, Li S, Shi Y. 2013. MicroRNA let-7d regulates the TLX/ microRNA-9 cascade to control neural cell fate and neurogenesis. Sci Rep 3: 1329.

Received April 3, 2017; accepted in revised form May 18, 2017. 


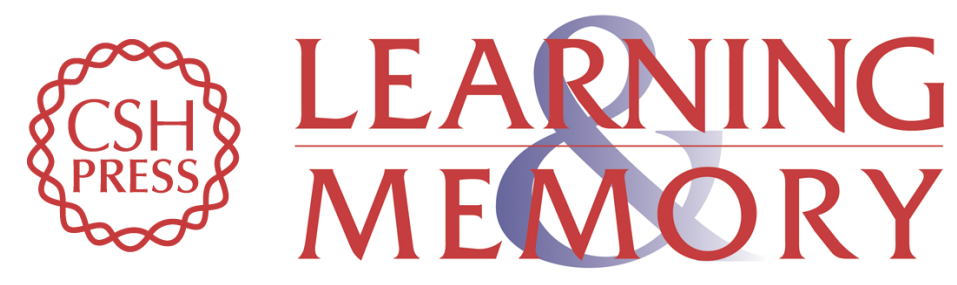

\section{Developmental pathway genes and neural plasticity underlying emotional learning and stress-related disorders}

Marissa E. Maheu and Kerry J. Ressler

Learn. Mem. 2017, 24:

Access the most recent version at doi:10.1101/lm.044271.116

References This article cites 126 articles, 31 of which can be accessed free at: http://learnmem.cshlp.org/content/24/9/492.full.html\#ref-list-1

Creative This article is distributed exclusively by Cold Spring Harbor Laboratory Press for the Commons first 12 months after the full-issue publication date (see

License http://learnmem.cshlp.org/site/misc/terms.xhtml). After 12 months, it is available under a Creative Commons License (Attribution-NonCommercial 4.0 International), as described at http://creativecommons.org/licenses/by-nc/4.0/.

Email Alerting Receive free email alerts when new articles cite this article - sign up in the box at the Service top right corner of the article or click here. 